\title{
Use of Polyacrylamide Hydrogel for Vesicoureteral Reflux Treatment, a Review
}

\author{
Francis Lemire', Anne-Sophie Blais', Katherine Moore' and Stephane Bolduc'* \\ 'Division of Urology, Department of Surgery, CHU de Québec - Université Laval Research Center, Québec, Canada
}

\section{Article Info}

\section{Article Notes}

Received: August 24, 2019

Accepted: November 04, 2019

\section{*Correspondence:}

Dr. Stéphane Bolduc, CHU de Quebec - Universite Laval 2705 Boulevard Laurier, R-1742 Québec, QC, G1V 4G2; Email: Stephane.Bolduc@fmed.ulaval.ca.

-2019 Bolduc S. This article is distributed under the terms of the Creative Commons Attribution 4.0 International License.

Keywords: Polyacrylamide hydrogel

vesicoureteral reflux

pediatric

urology

bulking agent

endoscopic injection

\section{Abstract}

Purpose of the review: Vesicoureteral reflux (VUR) is a common pathology encountered in pediatric urology. If left untreated, this condition can lead to infectious complications, hypertension and loss of renal function by scars. There is a trend for minimally invasive procedures to minimise treatmentrelated complications. Endoscopic subureteral injection of bulking agent in the treatment of VUR is an example of minimally invasive options. Several bulking agents have been studied and the perfect agent has not yet been discovered. Polyacrylamide hydrogel is a relatively new agent used to treat VUR and its use will be reviewed.

Recent findings: Three modern studies from a Canadian group have evaluated the use of polyacrylamide hydrogel for endoscopic injection to treat VUR. The first study reported a cure rate of $81.2 \%$ without major complication. In the second study, injection of polyacrylamide hydrogel was compared to dextranomer hyaluronic acid and no significant difference was observed, with overall success rate of $73.1 \%$ and $77.5 \%$ respectively. The third trial evaluated the long-term efficacy and safety of polyacrylamide hydrogel with a 36-month follow-up. Overall success at 3 months was $70.7 \%$ and no patient had de novo hydronephrosis or calcification of the agent at 36 months.

Conclusion: Polyacrylamide hydrogel seems to be a safe and effective alternative bulking agent in the treatment of VUR. The contribution from other centers to validate those data would be valuable.

\section{Introduction}

Vesicoureteral reflux (VUR) is frequently encountered in pediatric urology practice and overall estimated prevalence is between 1 and $3 \%{ }^{1,2}$. The clinical correlation of retrograde flow of urine with pyelonephritis was first described in the 1950s-1960s by Hutch ${ }^{3}$. Nowadays, renal scarring and loss of renal function due to VUR with UTI is well established. Moreover, the leading cause of hypertension in children and young adult is renal scarring or dysplasia secondary to VUR ${ }^{4}$. The objectives to manage this pathology aim to prevent recurrent febrile UTIs, prevent renal injury and minimize the morbidity associated with different treatment options and follow-up ${ }^{5}$. Management options are: active surveillance, continuous antibiotic prophylaxis, endoscopic injections of bulking agents and open, laparoscopic or robotic ureteral reimplantation ${ }^{5,6}$.

Endoscopic injection of bulking agents has been the subject of several publications during the last three decades and is now a well-accepted surgical option ${ }^{7-10}$. In 1984, Puri and O'Donnell reported for the first time, treatment of VUR in piglet by 
intravesical injection of polytetrafluoroethylene (PTFE, Teflon $®)^{11}$. Several bulking agents have been studied since then, including dextranomer hyaluronic acid (Dx/ HA, Deflux $\left.{ }^{\circledR}\right)^{12}$, polyacrylate-polyalcohol copolymer (PPC, Vantris ()$^{13}$, polydimethylsiloxane (Macroplastique ()$^{14}$, polytetrafluoroethylene (PTFE, Teflon $\AA)^{15}$, bovine collagen $^{16}$, calcium hydroxyapathite ${ }^{17}$ and autologous materials like chondrocytes ${ }^{18}$, fat ${ }^{19}$ and blood ${ }^{10,20}$. More recently, polyacrylamide hydrogel (PAHG, Bulkamid®) has been evaluated for the treatment of VUR by endoscopic injection ${ }^{21}$. The perfect bulking agent has not yet been identified, but should be biocompatible, nontoxic, nonantigenic, non-migratory, causing minimal inflammation, no calcification and keeping its shape and volume ${ }^{22}$. This article will review the use of polyacrylamide hydrogel as an alternative bulking agent in endoscopic treatment of children with VUR.

\section{Endoscopic Treatment of VUR}

Endoscopic injection of bulking agent is an attractive option for surgeons and patients/family. This procedure is less invasive than ureteral reimplantation, the operative time is shorter, no incision is needed and the intervention is usually made as an outpatient procedure. Endoscopic injection of biocompatible agent is believed to reduce reflux by adding a wall support to the ureter and narrowing the ureterovesical junction, without causing obstruction ${ }^{8}$. In a randomized clinical trial, Garcia-Aparicio et al. concluded that endoscopic injection of Dx/HA and Cohen's ureteral reimplantation were of similar effectiveness at five years follow-up ${ }^{23}$. Several studies compared the efficacy of ureteral reimplantation vs endoscopic injection in VUR, but conclusions remain controversial, especially for low-grade $\mathrm{VUR}^{23-25}$. In general, ureteral reimplantation offers higher success rates than endoscopic injection but comes with more morbidities.

O'Donnell and Puri described the Subureteral Teflon Injection (STING) technique in $1984^{15}$. In this technique, a bulking agent was injected $2-3 \mathrm{~mm}$ below the ureteral orifice with an 18-gauge needle through a 14 French cystoscope. In 2004, Kirsh et al. introduced the Hydrodistension Implantation Technique (HIT) where a submucosal injection is made within the ureteral orifice at the 6 o'clock position $^{26}$. Nowadays, the double HIT technique is the most popular among urologists ${ }^{27}$. In this method, the first injection is made within the ureteral tunnel, reducing the lumen proximally, and a second injection is performed in the distal tunnel to narrow the ureteral orifice ${ }^{28}$. If needed, additional injections with the STING technique can be made after a double HIT method ${ }^{28}$. Studies have shown better results with HIT and double HIT techniques, but a greater volume of bulking agents was needed, further increasing the cost of the procedure ${ }^{27-31}$.

\section{Polyacrylamide Hydrogel as an Alternative Bulking Agent for VUR}

In 2001, dextranomer hyaluronic acid (Dx/HA), commonly called Deflux®, obtained FDA approval for endoscopic treatment of VUR and became the most widely used bulking agent ${ }^{7,8}$. Success rate are ranging between $68 \%$ and $92 \%$ and better success rates correlate with lower grade of VUR ${ }^{7}$. A systematic review conducted by Routh et al. in 2010 revealed an overall success rate of $77 \%$, which means that about one quarter of treated patients will need additional procedures ${ }^{32}$.

PAHG has been widely injected around the urethra for the treatment of female stress urinary incontinence. A systematic review conducted by Kasi et al. concluded that it was an effective and safe treatment option ${ }^{22}$. Treatment of VUR by endoscopic injection of PAHG obtained approval in Canada in October 2017, which is currently the only country to have given this approval ${ }^{33}$. Three contemporary studies have evaluated the use of PAHG injections in endoscopic treatment in $\mathrm{VUR}^{21,34,35}$.

Cloutier et al. in 2013 was the first group to publish pediatric management of VUR with PAHG in the English scientific literature ${ }^{21}$. In this series, 40 patients $(30$ females, 10 males) underwent endoscopic injection of PAHG to treat VUR. Children with unilateral or bilateral VUR, primary or secondary reflux, first or second injection, previous surgical procedure and duplicated systems were included. Patients with neurogenic bladder and/or untreated voiding dysfunction were excluded. Preoperative evaluation included VCUG, renal bladder ultrasound (RBUS) and DMSA scan when deemed necessary. A single skilled surgeon performed the double HIT technique with patients under general anesthesia. Follow-up included VCUG, RBUS 3 month postoperatively and RBUS 1 year postoperatively. A total of 69 refluxing renal units were treated. When using up to 2 injections, the overall cure rate, defined as grade 0 reflux, was $81.2 \%$. A total of 6 refluxing renal units underwent a second injection. This cure rate differed according to the grade, ranging from $60 \%$ for grade $V$ to $100 \%$ for grade I. One patient suffered from pyelonephritis 3 weeks after surgery and no patient had evidence of obstruction after a mean follow-up of 12 months. Results were interpreted as comparable to the outcomes of Dx/HA, but limitations were relatively short follow-up and absence of comparative group.

A second trial from the same group was published by Blais et al. in $2015^{34}$. The aim of this study was to compare the efficacy of PAHG and Dx/HA in endoscopic treatment of VUR. For this purpose, a single center and single surgeon prospective non-randomized study was designed. Patients under 18 years of age with grade I to IV VUR confirmed by VCUG were included. Exclusion criteria were grade V VUR, 
previous endoscopic treatment, active infection, untreated dysfunctional elimination syndrome, neurogenic bladder and history of bladder exstrophy. The choice of the agent was based on product availability and alternate use of the two bulking agents was promoted. A total of 45 patients were included in each group, 78 refluxing renal units in the PAHG group and 71 in the Dx/HA. The overall success rate after the first injection was $73.1 \%$ with PAHG and $77.5 \%$ with Dx/HA ( $p=0.54)$ at the 3-month VCUG. One patient in each group suffered from febrile UTI after surgery. In the Dx/HA group, 2 patients developed symptomatic ureteral obstruction and one needed temporary ureteral stenting.

The last trial from the same institution was published by Ramsay et al. in 2017 and evaluated the long-term results and safety of PAHG in endoscopic treatment of VUR $^{35}$. A prospective single-surgeon study was designed to evaluate PAHG in endoscopic treatment of grade I to $\mathrm{V}$ VUR. Patients were included in this trial after exiting previous studies. All children had a VCUG and RBUS prior to surgery. DMSA scan was performed only when it was considered necessary. The same double-HIT technique was performed. Follow-up included VCUG and RBUS at 3 months, followed by RBUS at 12 and 36 months. To avoid unnecessary radiation and invasive manipulation, VCUG was not systematically repeated at one and three year. Success was defined by the absence of both VUR and de novo or worsening hydronephrosis. Authors looked at the complications to assess the safety of the procedure, such as calcification of the injected agent and febrile UTIs. A total of 76 patients (53 females, 23 males) with a median age of 45 months were included. The median volume of PAHG injected per refluxing renal unit was $1.0 \mathrm{ml}$, with volumes ranging from 0.6 to $2.5 \mathrm{ml}$. Overall success rates at 3 months were $70.7 \%$ for grades I to $\mathrm{V}$ and $72.6 \%$ when excluding grade $\mathrm{V}$. Success rates were higher for patients with a duplicated renal system $(87.5 \%)$, history of renal reimplantation $(100 \%)$ and history of previous injection with another agent (80\%). Only 2 patients experienced febrile UTI and only one had persistent VUR at the 3-month VCUG. At the 36-month RBUS follow-up, no patient had developed de novo or worsening hydronephrosis or calcification of the bulking agent and no case of ureteral obstruction were reported.

The only trial from a different group regarding the use of PAHG for endoscopic injection of VUR is a 1999 Russian article for which only the abstract is available in Pubmed ${ }^{36}$. In this study, 11 patients underwent 16 surgeries with Interfall injection, a PAHG variant. The success rate for VUR was $75 \%, 80 \%$ and $50 \%$ for grade II to IV, respectively. After discussion with the senior author, it was confirmed that more patients were also treated, but unfortunately, no data was collected.

All these studies show an interesting new purpose for PAHG. Its use in VUR treatment appears safe, with few reported febrile UTIs and no evidence of ureteral obstruction following the injection. Also, because PAHG is a nondegradable water-based polymer gel with high viscoelasticity and without small particles, it decreases the long-term risk of migration and calcification ${ }^{22,37}$. A $25 \%$ volume reduction after injection of Dx/HA has been described, leading to an increase in the quantity of bulking agent used ${ }^{38,39}$. The volume of PAHG has been shown to be stable several years after cosmetic surgeries, which is also promising for long-term results ${ }^{40,41}$. As previously mentioned, Routh et al. reported in their meta-analysis an overall success rate of $77 \% 3$ months after one injection of $\mathrm{Dx} / \mathrm{HA}^{32}$. Blais et al. obtained a success rate of $77.5 \%$ with $\mathrm{Dx} / \mathrm{HA}$, which was similar to Routh et al.'s results. However, these results were not significantly different from the rates obtained with PAHG. Ramsay et al. reported a median injected volume of PAHG of $1.0 \mathrm{ml}$ per refluxing renal unit, with volumes ranging from $0,6 \mathrm{ml}$ to $2,5 \mathrm{ml}$. In a recent article, Moore and Bolduc compared polydimethylsiloxane (Macroplastique ${ }^{\circledR}$ ) with $\mathrm{Dx} / \mathrm{HA}$ and they reported a median volume of $1.0 \mathrm{ml}$ for both agents with a range from 0.5 to $2.6 \mathrm{ml}$ and 0.5 to $2.8 \mathrm{ml}$ respectively ${ }^{42}$. Since the mean volume of bulking agent used to inject a refluxing renal unit was very similar for all the bulking agents, the price per $\mathrm{ml}$ of each different agent may have a direct impact on the cost of the procedure. In Canada, $1.0 \mathrm{ml}$ of PAHG costs $15-20 \%$ less than the same amount of $\mathrm{Dx} / \mathrm{HA}^{35}$.

\section{Conclusion}

Vesicoureteral reflux is a major concern in pediatric urology and management aim to prevent consequences without creating new comorbidities. Efforts have been made to found minimal invasive treatments and endoscopic injection of bulking agent is one of them. Among all agents studied, dextranomer hyaluronic acid remains the most popular. Polyacrylamide hydrogel has been studied as an alternative bulking agent and showed comparable results at 3 years follow-up. Furthermore, no ureteral obstruction and no calcification of injected PAHG were observed. These complications are two major concerns for pediatric urologists. PAHG is therefore an attractive alternative bulking agent for VUR treatment. The contribution of other centers to evaluate the use of PAHG for endoscopic injection of VUR would be valuable. Moreover, additional studies are needed to evaluate the longer-term efficacy and safety of PAHG in VUR.

\section{References}

1. Lebowitz RL. The detection and characterization of vesicoureteral reflux in the child. J Urol. 1992; 148(5 Pt 2): 1640-2.

2. Smellie JM, Poulton A, Prescod NP. Retrospective study of children with renal scarring associated with reflux and urinary infection. BMJ. 1994; 308(6938): 1193-6.

3. HUTCH JA, MILLER ER, HINMAN F. Vesicoureteral reflux. Role in pyelonephritis. Am J Med. 1963; 34: 338-49. 
4. Jacobson SH, Hansson S, Jakobsson B. Vesico-ureteric reflux: occurrence and long-term risks. Acta Paediatr Suppl. 1999; 88(431): 22-30.

5. Peters CA, Skoog SJ, Arant BS, et al. Summary of the AUA Guideline on Management of Primary Vesicoureteral Reflux in Children. J Urol. 2010; 184(3): 1134-44.

6. Wein AJ, Kavoussi LR, Partin AW, et al. Campbell-Walsh Urology. Eleventh ed. Philadelphia; 2016.

7. Chertin B, Kocherov S, Chertin L, et al. Endoscopic bulking materials for the treatment of vesicoureteral reflux: a review of our 20 years of experience and review of the literature. Adv Urol. 2011; 2011: 309626.

8. Diamond DA, Mattoo TK. Endoscopic treatment of primary vesicoureteral reflux. N Engl J Med. 2012; 366(13): 1218-26.

9. Fuentes S, Gómez-Fraile A, Carrillo-Arroyo I, et al. Endoscopic Treatment of Vesicoureteral Reflux in Infants. Can We Do It and Should We Do It? Urology. 2017; 110: 196-200.

10. Sugiyama T, Hanai T, Hashimoto K, et al. Long-term outcome of the endoscopic correction of vesico-ureteric reflux: a comparison of injected substances. BJU Int. 2004; 94(3): 381-3.

11. Puri P, O'Donnell B. Correction of experimentally produced vesicoureteric reflux in the piglet by intravesical injection of Teflon Br Med J Clin Res Ed. 1984; 289(6436): 5-7.

12. Stenberg A, Läckgren G. A new bioimplant for the endoscopic treatment of vesicoureteral reflux: experimental and short-term clinical results. J Urol. 1995; 154(2 Pt 2): 800-3.

13. Ormaechea M, Ruiz E, Denes E, et al. New tissue bulking agent (polyacrylate polyalcohol) for treating vesicoureteral reflux: preliminary results in children. J Urol. 2010; 183(2): 714-7.

14. Lorenzo AJ, Pippi Salle JL, Barroso U, et al. What are the most powerful determinants of endoscopic vesicoureteral reflux correction? Multivariate analysis of a single institution experience during 6 years. J Urol. 2006; 176(4 Pt 2): 1851-5.

15. O’Donnell B, Puri P. Treatment of vesicoureteric reflux by endoscopic injection of Teflon. Br Med J Clin Res Ed. 1984; 289(6436): 7-9.

16. Lipsky H, Würnschimmel E. Endoscopic treatment of vesicoureteric reflux with collagen. Five years' experience. Br J Urol. 1993; 72(6): 965-8.

17. Tarcan T, Tinay I, Temiz Y, et al. Long-term results of endoscopic treatment of vesicoureteral reflux with the sub-ureteric injection of calcium hydroxyapatite. Int Urol Nephrol. 2007; 39(4): 1011-4.

18. Caldamone AA, Diamond DA. Long-term results of the endoscopic correction of vesicoureteral reflux in children using autologous chondrocytes. J Urol. 2001; 165(6 Pt 2): 2224-7.

19. Chancellor MB, Rivas DA, Liberman SN, et al. Cystoscopic autogenous fat injection treatment of vesicoureteral reflux in spinal cord injury. Am Paraplegia Soc. 1994; 17(2): 50-4.

20. Kohri K, Umekawa T, Esa A, et al. Long-term results and curative mechanisms of vesicoureteral reflux by endoscopic injection of blood. Urology. 1989; 34(5): 258-61.

21. Cloutier J, Blais AS, Moore $\mathrm{K}$, et al. Prospective study using a new bulking agent for the treatment of vesicoureteral reflux: polyacrylamide hydrogel. J Urol. 2013; 190(3): 1034-7.

22. Kasi AD, Pergialiotis V, Perrea DN, et al. Polyacrylamide hydrogel (Bulkamid®) for stress urinary incontinence in women: a systematic review of the literature. Int Urogynecol J. 2016; 27(3): 367-75.

23. Garcia-Aparicio L, Rovira J, Blazquez-Gomez E, et al. Randomized clinical trial comparing endoscopic treatment with dextranomer hyaluronic acid copolymer and Cohen's ureteral reimplantation for vesicoureteral reflux: long-term results. J Pediatr Urol. 2013; 9(4): 483-7.

24. Esposito C, Escolino M, Lopez M, et al. Surgical Management of Pediatric Vesicoureteral Reflux: A Comparative Study Between Endoscopic, Laparoscopic, and Open Surgery. J Laparoendosc Adv Surg Tech A. 2016; 26(7): 574-80.

25. Oberson C, Boubaker A, Ramseyer P, et al. Endoscopic and surgical treatment of vesico-ureteral reflux in children. Comparative longterm follow-up. Swiss Med Wkly. 2007; 137(33-34): 471-5.

26. Kirsch AJ, Perez-Brayfield M, Smith EA, et al. The modified sting procedure to correct vesicoureteral reflux: improved results with submucosal implantation within the intramural ureter. J Urol. 2004; 171(6 Pt 1): 2413-6.

27. Kirsch AJ, Arlen AM, Lackgren G. Current trends in dextranomer hyaluronic acid copolymer (Deflux) injection technique for endoscopic treatment of vesicoureteral reflux. Urology. 2014; 84(2): 462-8.

28. Kalisvaart JF, Scherz HC, Cuda S, et al. Intermediate to long-term follow-up indicates low risk of recurrence after Double HIT endoscopic treatment for primary vesico-ureteral reflux. J Pediatr Urol. 2012; 8(4): 359-65.

29. Akin M, Erginel B, Karadag CA, et al. A comparison of the double hydrodistention implantation technique (HIT) and the HIT with a polyacrylate/polyalcohol copolymer (PPC) for the endoscopic treatment of primary vesicoureteral reflux. Int Urol Nephrol. 2014; 46(11): 2057-61.

30. Cerwinka WH, Scherz HC, Kirsch AJ. Dynamic hydrodistention classification of the ureter and the double hit method to correct vesicoureteral reflux. Arch Esp Urol. 2008; 61(8): 882-7.

31. Yap TL, Chen Y, Nah SA, et al. STING versus HIT technique of endoscopic treatment for vesicoureteral reflux: A systematic review and meta-analysis. J Pediatr Surg. 2016; 51(12): 2015-20.

32. Routh JC, Inman BA, Reinberg Y. Dextranomer/hyaluronic acid for pediatric vesicoureteral reflux: systematic review. Pediatrics. 2010; 125(5): 1010-9.

33. Agnew C. Government of Canada, Health Canada. 2017. https://www. canada.ca/en/health-canada.html (accessed 2019-04-14.

34. Blais AS, Morin F, Cloutier J, et al. Efficacy of dextranomer hyaluronic acid and polyacrylamide hydrogel in endoscopic treatment of vesicoureteral reflux: A comparative study. Can Urol Assoc J. 2015; 9(5-6): 202-6.

35. Ramsay S, Blais AS, Morin F, et al. Polyacrylamide Hydrogel as a Bulking Agent for the Endoscopic Treatment of Vesicoureteral Reflux: Long-Term Results and Safety. J Urol. 2017; 197(3 Pt 2): 963-7.

36. Barukhovich VIa, Shinkarenko VL, Rubizov IP, et al. [The application of endoscopic methods in the treatment of vesico-ureteral reflux in children with the use of polyacrylamide hydrogel "Interfall"]. Klin Khir. 1999; (3): 53-4.

37. Christensen LH, Nielsen JB, Mouritsen L, et al. Tissue integration of polyacrylamide hydrogel: an experimental study of periurethral, perivesical, and mammary gland tissue in the pig. Dermatol Surg. 2008; 34 Suppl 1: S68-77; discussion S.

38. Lee EK, Gatti JM, Demarco RT, et al. Long-term followup of dextranomer/ hyaluronic acid injection for vesicoureteral reflux: late failure warrants continued followup. J Urol. 2009; 181(4): 1869-74; discussion 74-5.

39. Sorensen MD, Koyle MA, Cowan CA, et al. Injection volumes of dextranomer/hyaluronic acid are increasing in the endoscopic management of vesicoureteral reflux. Pediatr Surg Int. 2010; 26(5): 509-13.

40. Christensen LH, Breiting VB, Aasted A, et al. Long-term effects of polyacrylamide hydrogel on human breast tissue. Plast Reconstr Surg. 2003; 111(6): 1883-90. 
41. Toozs-Hobson P, Al-Singary W, Fynes M, et al. Two-year followup of an open-label multicenter study of polyacrylamide hydrogel (Bulkamid®) for female stress and stress-predominant mixed incontinence. Int Urogynecol J. 2012; 23(10): 1373-8.
42. Moore K, Bolduc S. Prospective study of polydimethylsiloxane vs dextranomer/hyaluronic acid injection for treatment of vesicoureteral reflux. J Urol. 2014; 192(6): 1794-9. 